\title{
Qualification of the Low-pressure Cold Gas Spraying for the Additive Manufacturing of Copper-Nickel-Diamond Grinding Wheels
}

\author{
W. Tillmann ${ }^{1} \cdot$ J. Zajaczkowski ${ }^{1} \cdot$ I. Baumann ${ }^{1} \cdot$ M. Kipp ${ }^{2} \cdot$ D. Biermann ${ }^{2}$
}

Submitted: 23 August 2021 /in revised form: 12 November 2021/Accepted: 18 November 2021/Published online: 5 December 2021 (C) The Author(s) 2021

\begin{abstract}
Grinding wheels are usually manufactured by powder metallurgical processes, i.e., by molding and sintering. Since this requires the production of special molds and the sintering is typically carried out in a continuous furnace, this process is time-consuming and cost-intensive. Therefore, it is only worthwhile for medium and large batches. Another influencing factor of the powder metallurgical process route is the high thermal load during the sintering process. Due to their high thermal sensitivity, superabrasives such as diamond or cubic boron nitride are very difficult to process in this way. In this study, a novel and innovative approach is presented, in which superabrasive grinding wheels are manufactured by thermal spraying. For this purpose, flat samples as well as grinding wheel bodies were coated by low-pressure (LP) cold gas spraying with a blend of a commercial $\mathrm{Cu}-\mathrm{Al}_{2} \mathrm{O}_{3}$ cold gas spraying powder and nickel-coated diamonds. The coatings were examined metallographically in terms of their composition. A well-embedded superabrasive content of $12 \%$ was achieved. After the spraying process, the grinding wheels were conditioned and tested for the grinding application of cemented carbides and the
\end{abstract}

This article is an invited paper selected from presentations at the 2021 International Thermal Spray Conference, ITSC2021, that was held virtually May 25-28, 2021 due to travel restrictions related to the coronavirus (COVID-19) pandemic. It has been expanded from the original presentation.

\footnotetext{
J. Zajaczkowski

jonas.zajaczkowski@tu-dortmund.de

1 Institute of Materials Engineering, TU Dortmund University, Dortmund, Germany

2 Institute of Machining Technology, TU Dortmund University, Dortmund, Germany
}

topographies of both the grinding wheel and the cemented carbide were evaluated. Surface qualities of the ground surface that are comparable to those of other finishing processes were reached. This novel process route offers great flexibility in the combination of binder and hard material as well as a cost-effective single-part and smallbatch production.

Keywords additive manufacturing - cold spraying · diamond grinding wheel $\cdot$ grinding $\cdot$ low pressure cold spraying

\section{Introduction}

For the production of customized and innovative tools for surface conditioning, there are special requirements (e.g., with regard to the coating thickness, adhesion, porosity, phase evolution and density) for MMC (metal matrix composite) coatings containing superabrasives, which cannot be achieved by conventional (hot) thermal spray processes. Cold gas spraying (CGS) provides a promising approach to deposit such coatings with the required characteristics and was therefore used in this study. In this process, compressed air or an inert gas is heated and expanded in a De Laval nozzle. Process temperatures typically range from room temperature up to about $800^{\circ} \mathrm{C}$, but CGS systems with higher process temperatures are also available on the market (Ref 1). The latter are mainly used for processing cermets such as WC-Co or high-strength nickel- or iron-based alloys. The spray materials are generally not melted. Rather, the comparatively low thermal energy is compensated by the deformation energy when the highly accelerated spray particles hit the substrate surface. The adhesion of individual splats is essentially based on the 
mechanical interlocking of the particles and on a phenomenon comparable to cold welding (Ref 2 ), although the specific mechanisms are still under discussion (Ref 3-5). If the kinetic energy of the particles is too low, no coating is formed. In this case, the spray particles, which are accelerated insufficiently, bounce off the surface. If the kinetic energy in turn is too high, the erosion speed is reached and, comparable to grit blasting, unwanted material removal of the substrate or coating material occurs. The kinetic energy or the velocity above which layer formation is possible is referred to as the "critical velocity" (Ref 1). For each material pairing of spray material and substrate material, different velocity windows exist in which a coating is formed.

A fundamental advantage of cold gas spraying is the low thermal energy transfer to the spray material (powder) and the substrate material. This means that even thermally sensitive materials can be sprayed or coated without notable thermal reactions. In addition, the equipment, especially in the area of low-pressure cold gas spraying (LP-CGS), is low priced and the investment and operating costs are low. Furthermore, high coating thicknesses can be realized due to the low thermally induced residual stresses. Since the lateral extent of the spray jet is narrow compared to other thermal spray processes due to the low spray jet divergence, a local coating of component areas can be realized. Due to the above-mentioned properties, cold gas spraying is regarded as an upcoming process in the field of additive manufacturing (Ref 6).

The basic feasibility of processing of hard materialmetal powder blends by means of thermal spray processes can be found in the available literature (Ref 7-9). In previous investigations, detonation flame spraying was initially used for production of diamond-coated tools for rock machining (Ref 10-12). With this method, it was possible

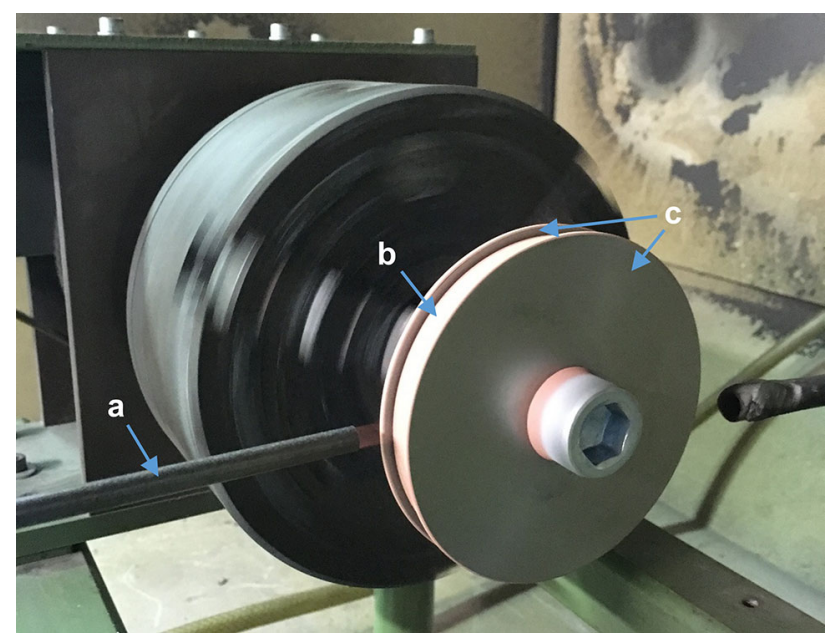

Fig. 1 Spraying setup for the grinding wheel blank: (a) spraying nozzle; (b) substrate; (c) flanges to embed large diamonds with a particle size range of $300-420 \mu \mathrm{m}$ (40/50 USmesh) in a copper matrix. However, the diamond content was lower (at 2 vol.- $\%$ ) compared to conventionally manufactured diamond-metal segments (powder metallurgical production, up to $10 \mathrm{vol} \%$ ). As a further development, high-velocity oxygen-fuel spraying (HVOF) for the application of diamond-metal composite coatings was investigated and modeled (Ref 13-15). The HVOF process showed great potential for the application of diamond-nickel composite coatings with small, nickelcoated diamond grains $(8-12 \mu \mathrm{m})$. Larger diamonds (40-60 $\mu \mathrm{m}$ grain size) could only be embedded in the coating with very low deposition efficiencies. Nevertheless, a coating is formed from the nickel, leading to the assumption that the large diamonds bounce off the surface while the molten nickel forms a coating on the surface. In addition, the HVOF process provided a low overall deposition efficiency (diamond and binder). For small diamond grit sizes, the nickel coating is sufficient to form a load-bearing coating with a diamond content of $33.5 \pm 2.5$ vol\% (Ref 13 ). Measurements by x-ray diffraction analysis showed that the nickel coating protects the diamond from graphitization or

Table 1 Parameters used for the LP-CGS process

\begin{tabular}{ll}
\hline Parameter & \multicolumn{1}{c}{ Value } \\
\hline Temperature & Setting $3\left(\sim 400{ }^{\circ} \mathrm{C}\right)$ \\
Gas inlet pressure & $6 \mathrm{bar}$ \\
Process gas & Compressed air \\
Powder feeder setting & 3 \\
Stand-off distance & $15 \mathrm{~mm}$ \\
Surface speed & $12,000 \mathrm{~mm} / \mathrm{min}$ \\
Track pitch & $1 \mathrm{~mm}$ \\
Number of passes & 5 \\
\hline
\end{tabular}

\section{a) Dressing process}

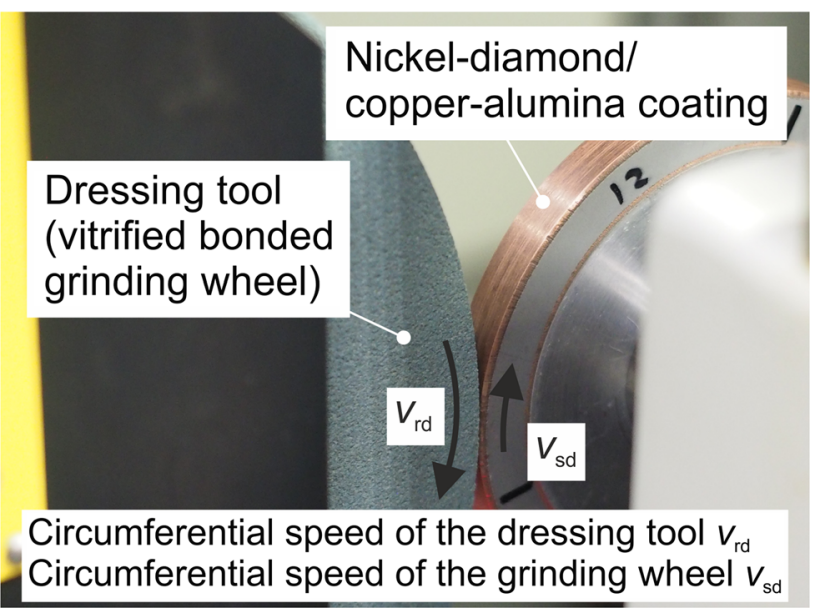

Fig. 2 Conditions of the dressing process 
decomposition. However, $\mathrm{NiO}$ was detected in the microstructure of the spray coating, which is formed by the atmospheric process conditions. In extended wear tests (pin-on-disk, ASTM G99), it could be demonstrated that the coating has properties corresponding to a grinding tool, based on the massive counterbody wear $\left(\mathrm{Al}_{2} \mathrm{O}_{3}\right.$ ball) (Ref 15). The thickness of the produced diamond composite coatings is in characteristic coating thickness ranges of $300-400 \mu \mathrm{m}$ for HVOF processes. Thicker coatings are not

Table 2 Dressing conditions

\begin{tabular}{ll}
\hline Parameter & Value \\
\hline Ratio of dressing speeds $q_{\mathrm{d}}$ & -0.8 \\
Overlapping rate $U_{\mathrm{d}}$ & 15 \\
Depth of dressing cut $a_{\mathrm{ed}}$ & $2 \mu \mathrm{m}$ \\
Dressing swings & 25 \\
Cooling lubricant & Emulsion \\
\hline
\end{tabular}
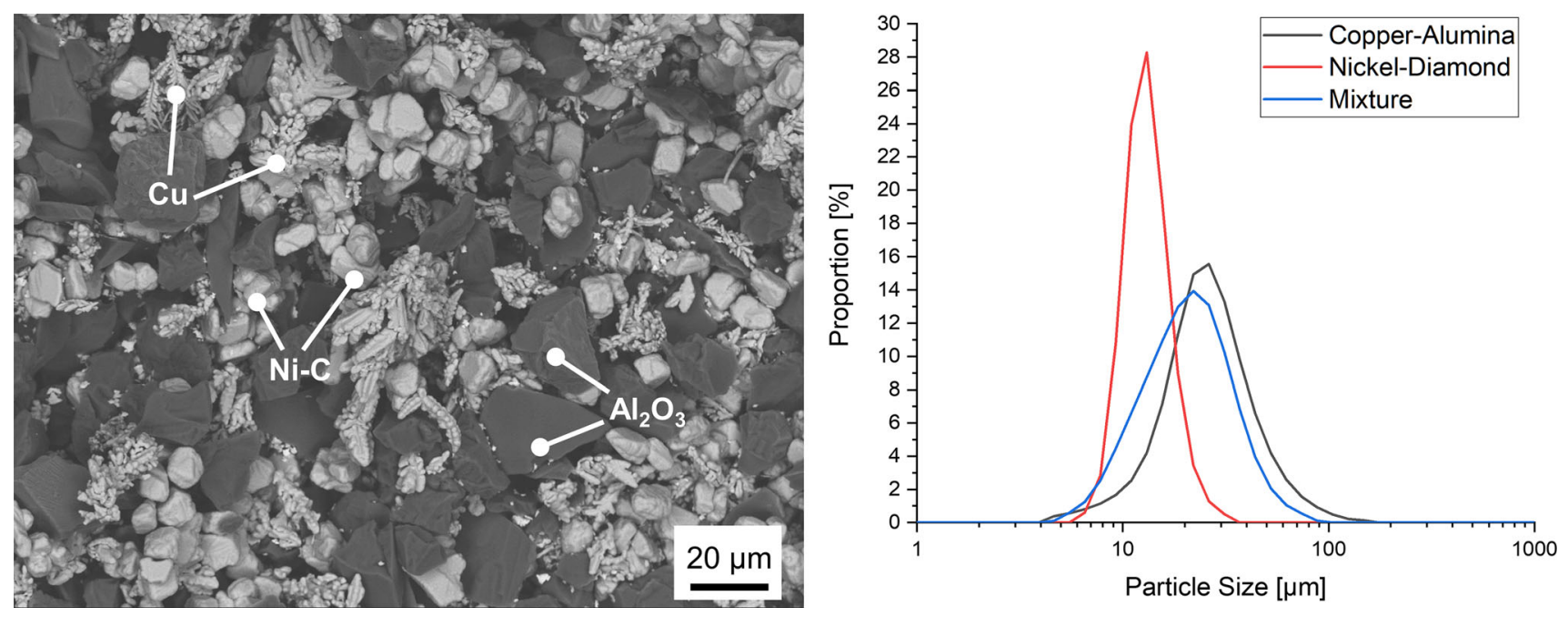

Fig. 3 SEM-Image (BSD, 500x magnification) of the $\mathrm{Cu}-\mathrm{Al}_{2} \mathrm{O}_{3}-(\mathrm{Ni}-\mathrm{C})$-powder blend (left); laser diffraction analysis of the powders and the mixture (right)

Fig. 4 (a) Coated grinding wheel body; (b) light microscopy image of cross section feasible due to the inherent residual stresses resulting from the process, which would result in delamination of the coating.

To achieve a higher coating thickness, which is a necessary requirement for the additive manufacturing of grinding wheels used for surface finishing, a low-pressure cold gas spraying process was used in this study. A mixture of nickel-coated diamonds, which were synthesized by the high-pressure-high-temperature (HTHP) process, and a

Table 3 Grinding conditions

\begin{tabular}{ll}
\hline Parameter & \multicolumn{1}{c}{ Value } \\
\hline Circumferential speed $v_{\mathrm{s}}$ & $15 \mathrm{~m} / \mathrm{s}$ \\
Feed rate $v_{\mathrm{f}}$ & $50 \mathrm{~mm} / \mathrm{min}$ \\
Depth of cut $a_{\mathrm{e}}$ & $10 \mu \mathrm{m} ; 20 \mu \mathrm{m}$ \\
Grinding strategy & Down grinding \\
\hline
\end{tabular}



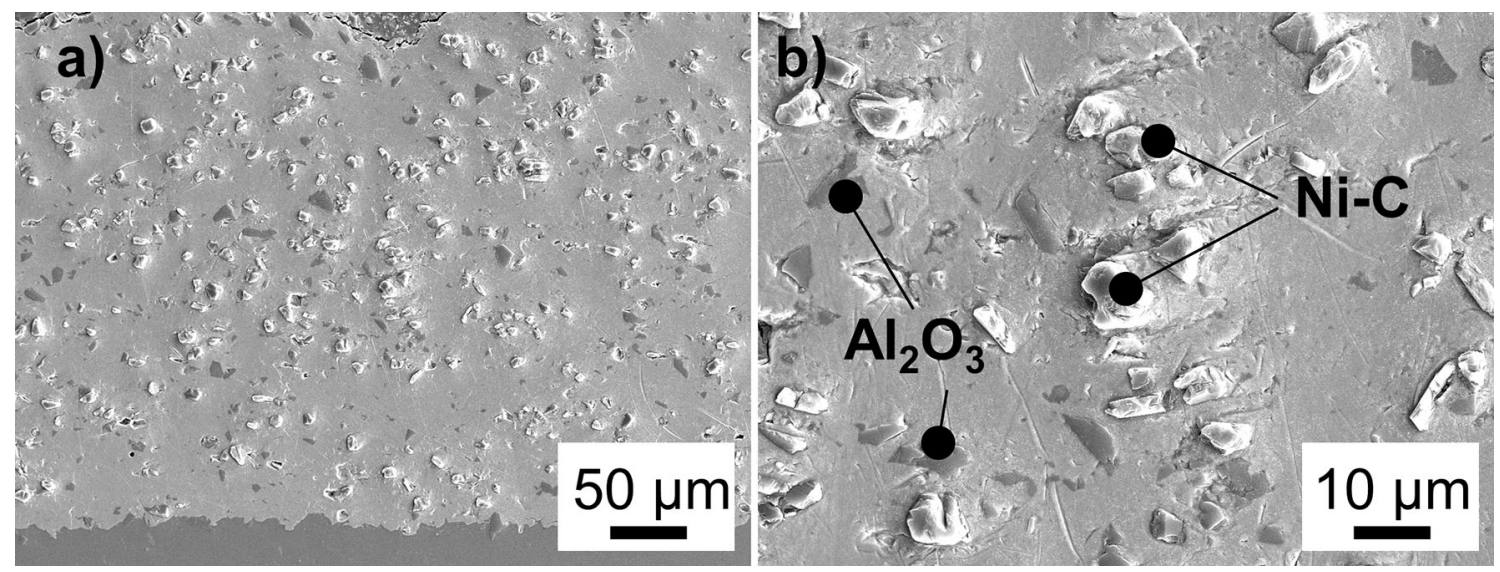

Fig. 5 SEM-Images of cross section; (a) 100x magnification; (b) 2000x magnification

Fig. 6 Calculated (ThermoCalc DICTRA) and observed (SEM/EDS) diffusion zones at the $\mathrm{Al}-\mathrm{Cu}$ interface
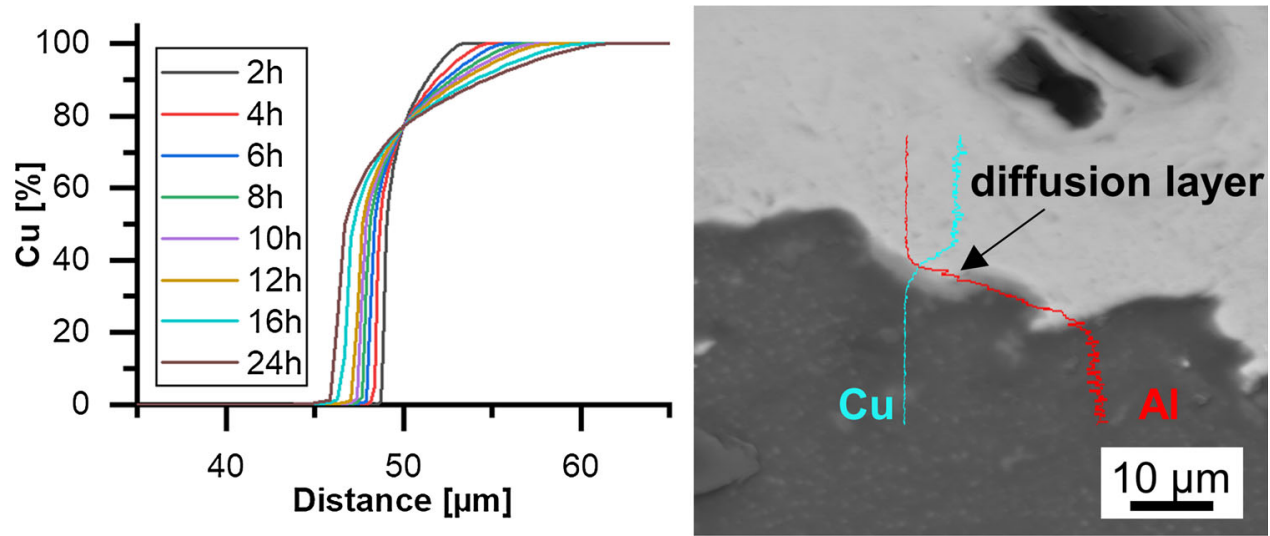

$\mathrm{Cu}-\mathrm{Al}_{2} \mathrm{O}_{3}$-powder was applied with a LP-CGS spraying system to achieve a coating thickness of $\sim 1.5 \mathrm{~mm}$. The coatings were subsequently heat treated to improve the interfacial bond as well as the coating cohesion. The produced coatings were examined metallographically regarding their composition by means of light microscopy and SEM/EDS as well as nondestructively by means of computer tomographic microscopy.

Additionally, tests concerning the dressing process of the novel grinding tools and grinding tests using cemented carbide as workpiece material were conducted. This approach makes it possible to assess whether the additively manufactured grinding wheels can withstand the stresses of a conditioning as well as a grinding process and have the potential to achieve surface qualities that are comparable to those of conventional grinding processes.

This novel approach makes it possible to manufacture grinding wheels economically in single-part or small-batch production. This enables the production of tools that are individually adapted to the respective application with regard to the grain size of the hard materials or binder content.

\section{Experimental}

To obtain a homogeneous powder mixture, the two powders (nickel-coated synthetic HTHP diamonds (Ni-C, 8-12 $\mu \mathrm{m}$ grain size, CM-M Ni60, Ceratonia GmbH \& Co. KG, Germany) as well as a commercial, LP-CGS-optimized $\mathrm{Cu}$ $\mathrm{Al}_{2} \mathrm{O}_{3}$-powder blend (K-01-01, Dycomet Europe B.V., Netherlands)) were mixed in a weight ratio of $1: 2$ in a 3D shaker mixer (T2C, WAB AG, Germany) for one hour. The powder mixture was then analyzed by means of a field emission scanning electron microscope (JSM 7001F, Jeol Ltd., Japan) utilizing a backscattered electron detector (BSD) as well as electron dispersive spectroscopy (EDS). Furthermore, the two base powders as well as the powder blend were investigated by laser diffraction particle size analysis (S3500, Microtrac Retsch GmbH, Germany).

To evaluate the coating microstructure and the effect of the heat treatment following the coating process, the end faces of round aluminum samples (Ø40 × $6 \mathrm{~mm}$, material AlSiMg0.5 / EN AW-6060) were pretreated for the coating process by grit blasting with EKF-40 corundum (grain size $355-500 \mu \mathrm{m})$ at a pressure of 4 bar and a distance of 100 $\mathrm{mm}$ at an angle of $45^{\circ}$. Subsequently, the samples were 
Fig. 7 Computed tomographic images of a section of the generated nickeldiamond/copper-alumina coating in the as-sprayed condition (a) and in the heattreated condition (b)
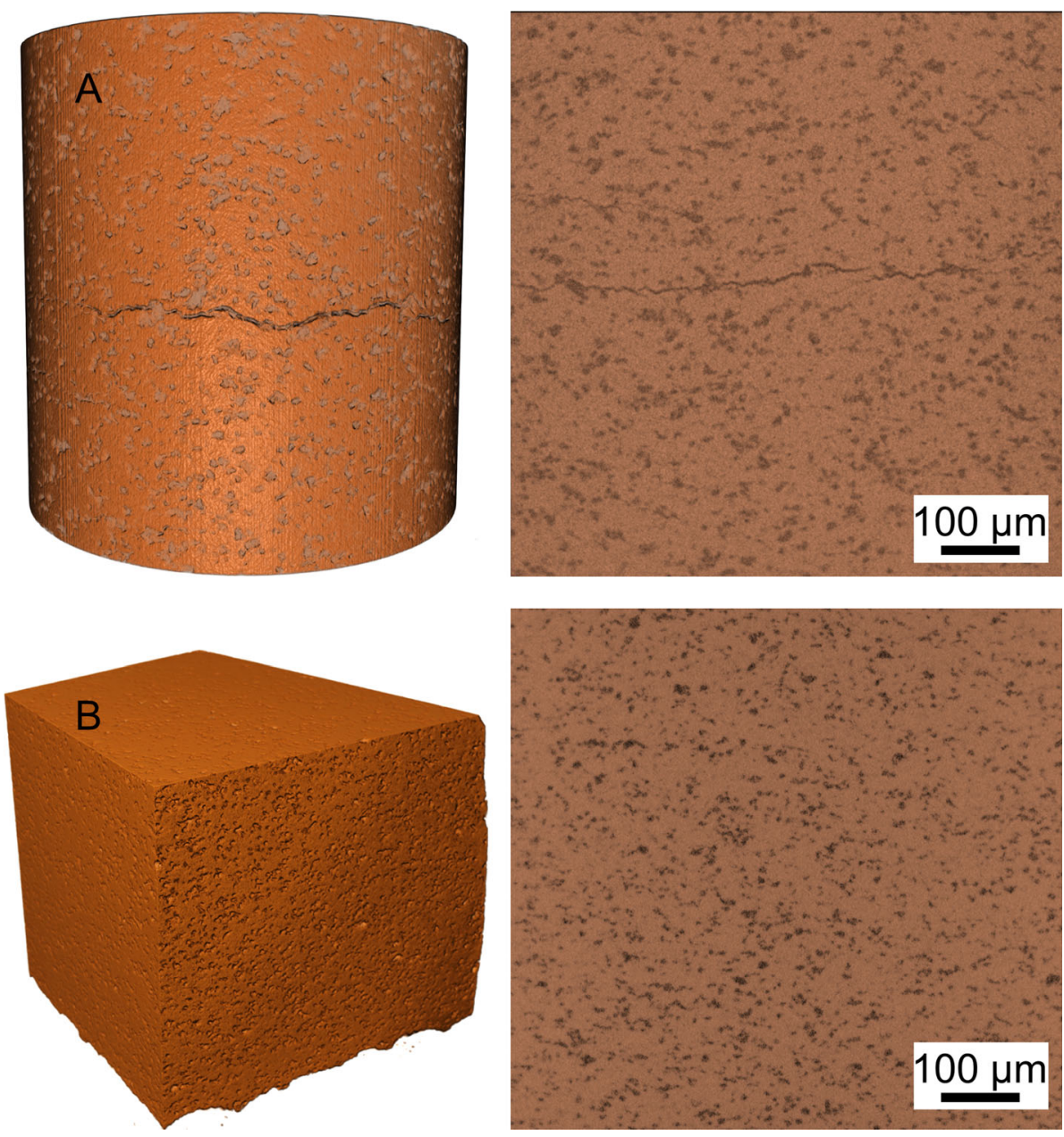

cleaned in an ethanol ultrasonic bath for 10 minutes. The outer cylinder surfaces of the aluminum grinding wheel blanks (inner diameter $20 \mathrm{~mm}$, outer diameter $87.5 \mathrm{~mm}$, width $10 \mathrm{~mm}$ for the first wheel used in the dressing test; inner diameter $20 \mathrm{~mm}$, outer diameter $80 \mathrm{~mm}$, width 10 $\mathrm{mm}$ for the second wheel used in the grinding test) were prepared by the same process.

Before clamping onto the lathe, the end faces of the grinding wheel blanks were covered with flanges to prevent the coating from beveling toward the edge due to gas flow effects and to achieve a uniform coating result (Fig. 1). The grinding wheel blank was then rotated at a speed of 43.7 $\mathrm{rpm}$ to achieve a surface speed of $12,000 \mathrm{~mm} / \mathrm{min}$. The LPCGS spray gun (DYMET 413, Dycomet Europe B.V., Netherlands) was moved tangentially at a distance of 15 $\mathrm{mm}$ at a speed of $43.7 \mathrm{~mm} / \mathrm{min}$ using an industrial robot (type IRB 4400-60/1.95, ABB Ltd., Switzerland). For the flat samples, the coating was applied with a meandering path with a track pitch of $1 \mathrm{~mm}$ and a tangential speed of $12,000 \mathrm{~mm} / \mathrm{min}$. The gas inlet pressure was $6 \mathrm{bar}$, and the temperature setting was set to level 3 (corresponding to ca.
$400{ }^{\circ} \mathrm{C}$ gas temperature at the nozzle inlet). The coating parameters can be found in Table 1.

In order to achieve a material bond in the form of a diffusion zone and thus to improve the coating adhesion, a heat treatment process was performed subsequently to the coating deposition. Diffusion calculations were carried out with the Thermo-Calc DICTRA software to design the heat treatment process. A moderate temperature of $300{ }^{\circ} \mathrm{C}$ was selected as process temperature in order to reduce the formation of brittle intermetallic compounds such as $\mathrm{AlCu}_{2}$. Based on the results of the diffusion calculations, a heat treatment process at $300^{\circ} \mathrm{C}$ for $24 \mathrm{~h}$ was carried out in an atmospheric furnace (N100, Nabertherm $\mathrm{GmbH}$, Germany).

The flat specimens were then used to prepare cross sections, which were subsequently examined by optical microscopy (BX51M, Olympus K.K., Japan), scanning electron microscopy (SEM) and energy-dispersive x-ray spectroscopy (EDS). Furthermore, smaller samples were cut from a flat specimen in the as-sprayed condition as well as from one in the heat-treated condition and nondestructively analyzed using an x-ray microscope (XRadia 520 
(a) Topography of the grinding layer after dressing
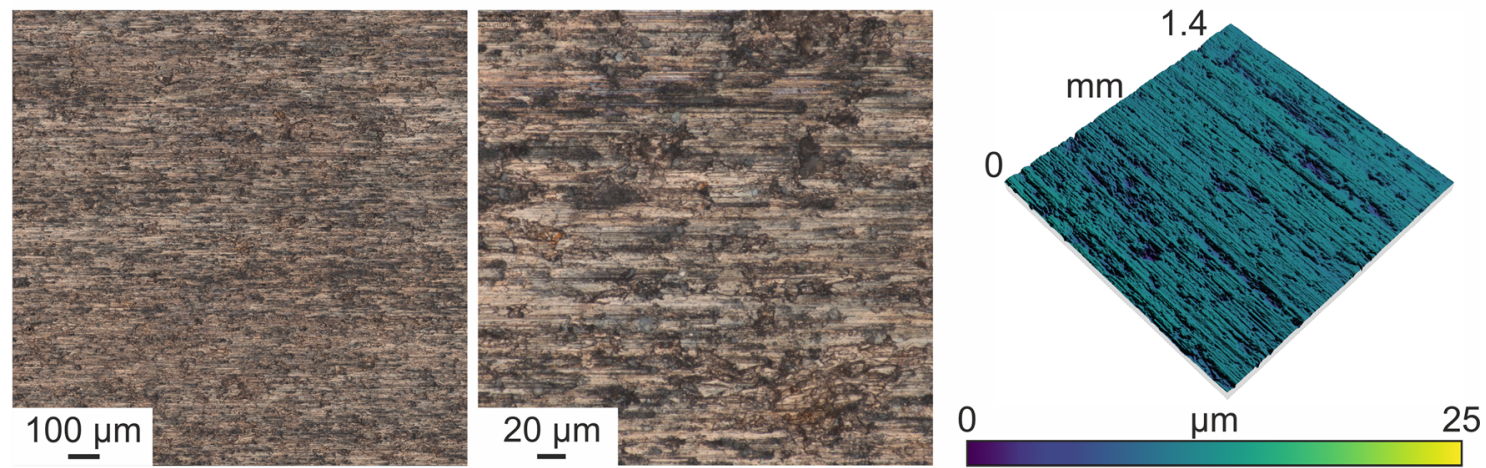

(b) Profile information of the topography

Height

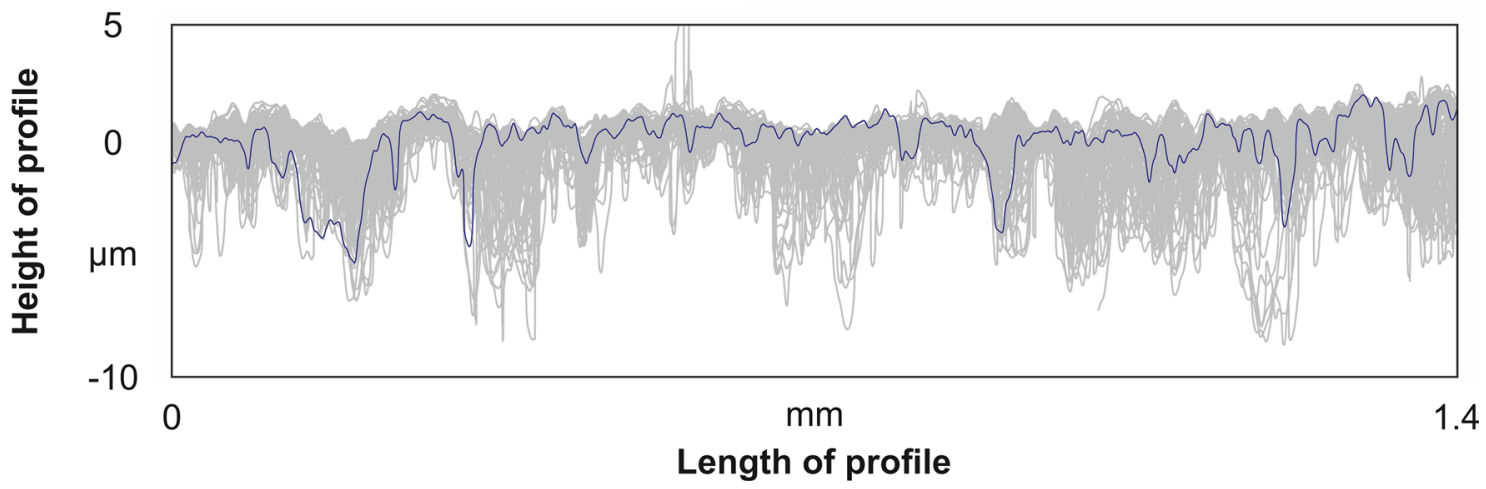

Fig. 8 Topography of the grinding layer after dressing

Versa, Carl Zeiss AG, Germany) with a maximum voxel resolution of $700 \mathrm{~nm}$. A total of 2400 images taken with a tube current of $140 \mathrm{kV}$, a power of $8 \mathrm{~W}$ and an exposure time of $10 \mathrm{~s}$ were combined to get the CT scans.

Nickel-coated diamonds with a grain size of $d_{\mathrm{g}}=8-12$ $\mu \mathrm{m}$ are embedded in the grinding layer produced by the low-pressure cold gas spraying process. Consequently, the tools are intended to be tested in a finishing operation. Due to the high coating thickness of about $1.5 \mathrm{~mm}$, it is possible to conduct a dressing process of the grinding tools, which is necessary to generate the required runout properties and to prepare the profile. These processes were conducted on a dressing machine type AP-800 Fusion (Rudolf Geiger Maschinenbau $\mathrm{GmbH}$ ). The dressing process was realized using a vitrified bonded silicon carbide grinding wheel (grain size F240) as a rotating dressing tool, which is a common process for the dressing of diamond grinding wheels (Ref 16). Figure 2 shows the setup of the dressing process.

A substantial influencing variable in dressing processes with rotating dressing tools is the ratio of the dressing speeds $q_{\mathrm{d}}(\operatorname{Ref} 17)$. This was set to $q_{\mathrm{d}}=-0.8$. Moreover, the overlapping rate in dressing was determined as $U_{\mathrm{d}} \approx$ 15 and the depth of dressing cut was $a_{\mathrm{ed}}=2 \mu \mathrm{m}$. As a result of 25 dressing swings, the total depth of the dressing cut was $a_{\text {ed,ges }}=50 \mu \mathrm{m}$. Emulsion was used as cooling lubricant for the dressing processes. Dressing conditions are summarized in Table 2. The tests conducted concerning the dressing processes focus the analysis of the grinding wheel topography. To this end, the grinding layer was analyzed using an optical measurement device (Alicona InfiniteFocus G5). The topography was examined at different levels of detail on six positions around the circumference of the grinding tool.

In a further step, one grinding wheel with a nickeldiamond/copper-alumina coating as grinding layer was tested in grinding processes, which were conducted on a tool grinding machine type 305micro (Alfred H. Schütte $\mathrm{GmbH} \& \mathrm{Co} . \mathrm{KG}$ ). Cemented carbide (WC-Co, $12 \% \mathrm{Co}$ ) with a grain size of $0.5 \mu \mathrm{m}$ was selected as the workpiece material. Due to the comparatively small diamond grains, the surface was pre-ground using a diamond-grinding wheel with a grain size of D64 for the examinations concerning the surface roughness. During the grinding tests, the circumferential speed of the grinding tool was set to $v_{\mathrm{s}}$ $=15 \mathrm{~m} / \mathrm{s}$ and the feed rate was $v_{\mathrm{f}}=50 \mathrm{~mm} / \mathrm{min}$. The depth of the cut was varied in two steps and is specified as $a_{\mathrm{e}}=10$ $\mu \mathrm{m}$ and $a_{\mathrm{e}}=20 \mu \mathrm{m}$. A summary of the grinding parameters is given in Table 3 . In order to examine whether a material removal is achieved and to what extend the surface 


\section{(a) Grinding layer}

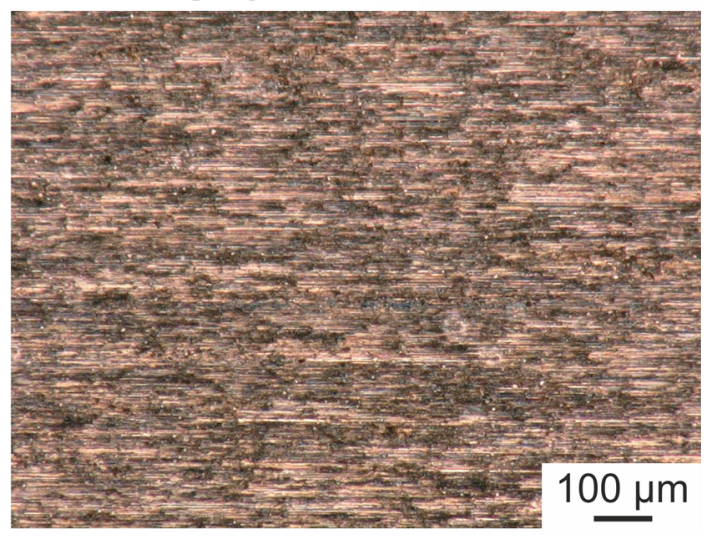

(b) Fine ground surface

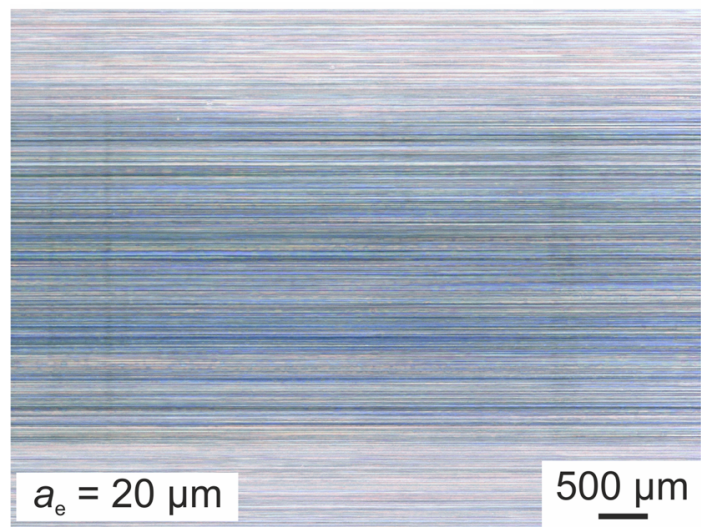

Fig. 9 Overview of the grinding layer after grinding process and of the ground surface of the cemented carbide

topography is affected, tactile roughness measurements were conducted. In addition, a white light microscope (NanoFocus $\mu$ surf) was used to analyze the surface topography of the ground cemented carbide in further detail.

\section{Results and discussion}

After the tumbling mixing process, the powder blend shows a homogeneous distribution of the individual components in the SEM images (Fig. 3). It can be seen that the copper powder is in a dendritic morphology, which is caused by the electrochemical manufacturing route. This dendritic morphology is an excellent prerequisite for embedding other particles in the cold sprayed coating that might otherwise not adhere in the coating, since the "arms" of the dendrites fragment during the spraying process and interlock well with other particles (Ref 18). The alumina particles can be seen as larger, sintered and broken particles, which are included in the powder blend to further densify the coating by means of a shot peening effect/mechanical hammering of the applied coating as well as to prevent nozzle clogging by abrading sticking material in the injector/nozzle during the low-pressure cold spraying process (Ref 19). The laser diffraction analysis shows a narrow particle size distribution for the nickelcoated diamonds $\left(\mathrm{d}_{10}=8.8 \mu \mathrm{m}, \mathrm{d}_{50}=11.8 \mu \mathrm{m}, \mathrm{d}_{90}=16.6\right.$ $\mu \mathrm{m})$ and a broader distribution for the copper-alumina powder $\left(\mathrm{d}_{10}=12.5 \mu \mathrm{m}, \mathrm{d}_{50}=23.3 \mu \mathrm{m}, \mathrm{d}_{90}=44.1 \mu \mathrm{m}\right)$. The powder blend shows a similar particle size distribution to the copper-alumina powder with slightly lower values for the characteristic diameters $\left(d_{10}=9.5 \mu \mathrm{m}, d_{50}=18.9 \mu \mathrm{m}\right.$, $\left.\mathrm{d}_{90}=34.8 \mu \mathrm{m}\right)$.

Figure 4 shows a macroscopic image of the coated aluminum base body. It can be clearly seen that a uniform, thick coating could be applied with only minor macro defects in the form of pittings, which can be attributed to smaller particles being diverted due to the bow shock effect (Ref 20,21). The light microscope images of a cross section of a flat sample in Fig. 4b show a largely defect-free coating without any discernible cracks or pores. Slight inhomogeneities in the hard material distribution can be seen in the micrograph (Fig. 4b). This indicates that a segregation process has taken place during the powder feeding process, leading to an uneven distribution.

The SEM images show good embedding of the nickeldiamond particles in the copper matrix (Fig. 5b). An image-analytical evaluation using the software framework ImageJ of a total of 5 cross section images (one being shown in Fig. 5a) further shows that the volumetric fraction of nickel-diamond particles is much lower than in the original powder blend with a value of only $12.5 \%$ compared to the original volumetric fraction of $28 \%$ in the blend. This suggests a low deposition efficiency for these particles and points to further optimization potential of the spray parameters for this powder blend.

The numeric calculations of the diffusion process at the coating-substrate interface $(\mathrm{Cu}-\mathrm{Al})$ using the Thermo-Calc DICTRA software suggested that a diffusion layer with a width of about $15 \mu \mathrm{m}$ should result after a 24-h-long heat treatment process at a temperature of $300{ }^{\circ} \mathrm{C}$ (Fig. 6a). However, in the SEM/EDS analysis, only small $(\sim 1 \mu \mathrm{m})$, very localized diffusion zones could be found at the $\mathrm{Al}-\mathrm{Cu}$ interface (Fig. 6b), suggesting that insufficient bonding and breakup of the naturally and quickly formed Al-oxide layer has occurred during the cold spraying process. It is assumed that much higher process gas pressures could overcome this problem, which, however, is not achievable with the used low-pressure cold gas spraying system.

The nondestructive testing shows a large crack through the center of the sample in the as-sprayed condition (Fig. 7a), which can be detected throughout the whole CT scan area. Since these cracks primarily spread between the hard material particles (aluminum oxide or diamond), it is 
Fig. 10 Roughness and topography of the ground surface of the cemented carbide

\section{(a) Surface roughness}

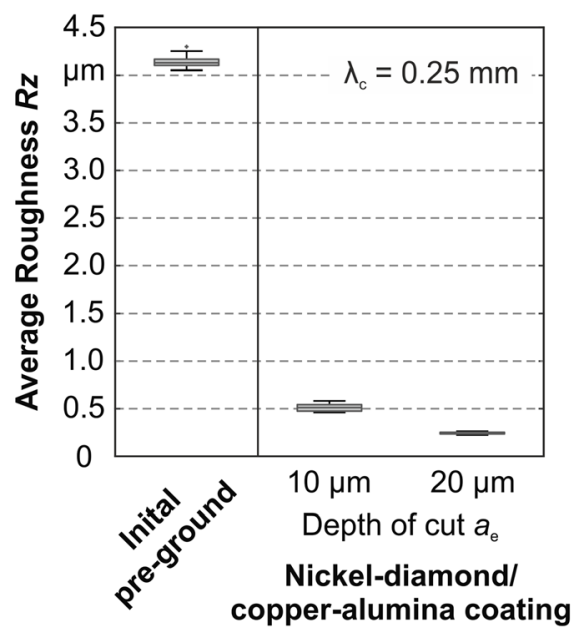

(b) Surface topography

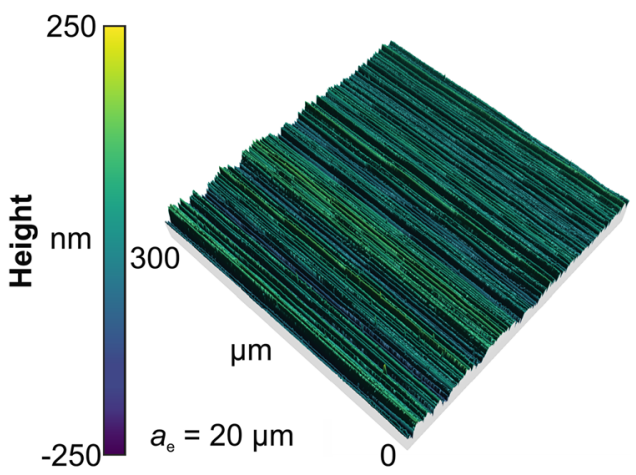

(c) Profile series

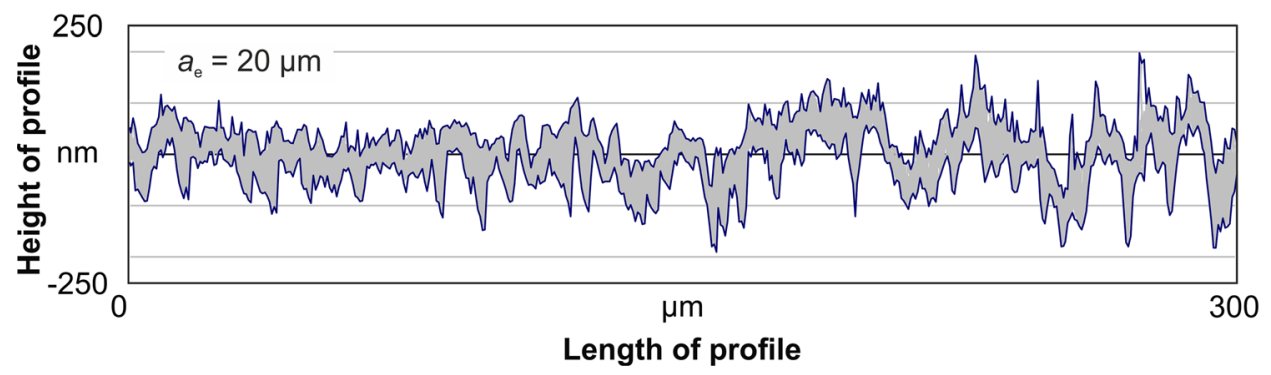

assumed that these particles significantly weaken the coating cohesion. Because these CT images were acquired in the as-sprayed condition (without heat treatment), the brittle behavior of the copper matrix, which has been extensively examined in other works (Ref 22, 23), also has a major influence on the cohesive strength of the coating. Further investigations with three heat-treated samples (one being shown in Fig. 7b) show no such major defects, suggesting that the heat-treated copper matrix shows a much more ductile behavior.

Figure 8 shows the topography of the grinding layer after the dressing process. Next to microscopic images in two different magnifications, the grinding tool surface is also shown with additional height information. After dressing, the nickel-diamond/copper-alumina coating shows a quite homogenous surface structure with small grooves and some small dimples. The three-dimensional picture illustrates this in more detail. During the dressing processes, spalling of the nickel-diamond/copper-alumina coating was not detected. Therefore, on the basis of the first tests, it can be concluded that conventional dressing processes are suitable for the conditioning of the novel grinding layers as well.

With regard to the following grinding process, the change of the surface roughness resulting from the impact of the novel grinding layer was examined. To this end, Fig. 9 shows microscopic pictures of the sprayed coating after the grinding process and of the ground surface. No spalling of the grinding layer could be detected during grinding under the conditions mentioned. The picture of the fine ground surface reveals an impression of the altered surface area caused by the nickel-diamond/copper-alumina coating. Due to the fine grain size, it is possible to create a smooth surface topography with reflective surface properties. Nonetheless, the uniformity of the material removal in combination with the grinding wheel profile should be investigated in further investigations.

To analyze the surface of the ground cemented carbide specimen in further detail, Fig. 10 provides information about the surface roughness and the surface topography. The surface roughness is quantified using the average roughness $R z$. In the initial state, the ground surface shows an average roughness of $R z=4.1 \mu \mathrm{m}$. Due to the finishing process, the surface roughness could be reduced to $R z=$ $0.24 \mu \mathrm{m}$ for a depth of cut of $a_{\mathrm{e}}=20 \mu \mathrm{m}$. The surface topography is typical for grinding processes, which becomes obvious due the linear scratches. In particular, this is apparent in Fig. 10(b) and (c). To gain further information about the material separation process when applying the nickel-diamond/copper-alumina coating, Fig. 11 
(a) Fine ground surface

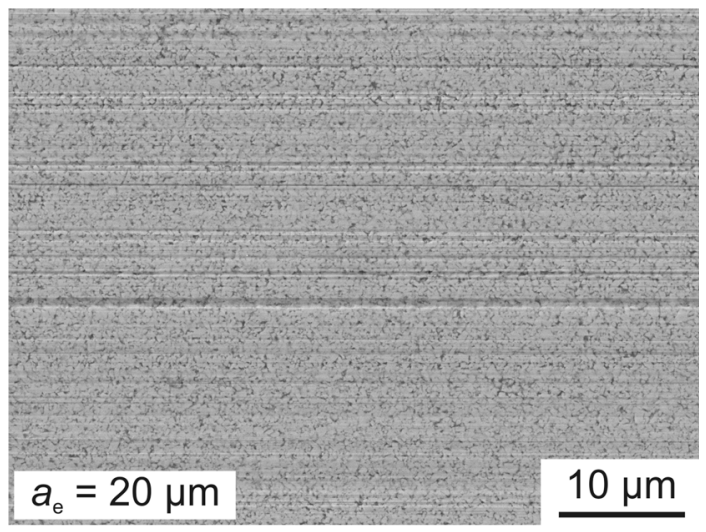

(b) Fine ground surface - detail

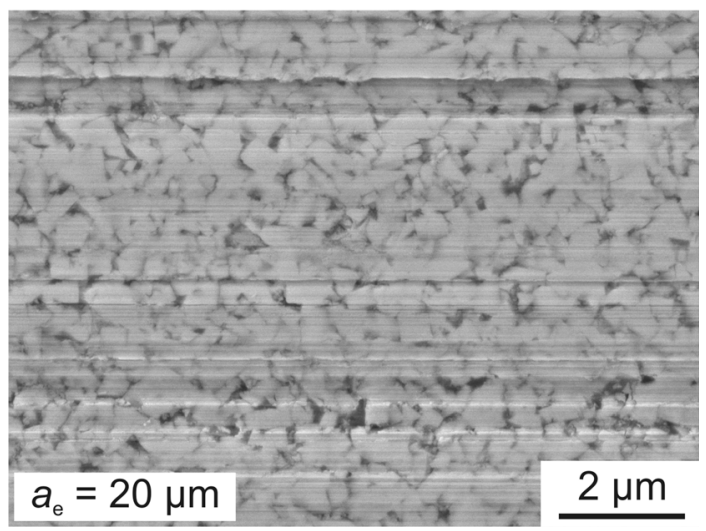

Fig. 11 SEM images of the ground surface of the cemented carbide

shows SEM images of the ground surface. The surface exhibits a homogenous topography with some distinct scratches, which might occur due to specific protruding grains in the grinding layer. Larger areas characterized by breakouts were not observed. The results concerning the surface roughness are comparable to research in the field of fine finishing processes for cemented carbides. Within the scope of the first grinding tests, a surface roughness in the range of other abrasive fine finishing processes could be achieved (Ref. 24).

With respect to the wear of the grinding wheel, microscopic images of the nickel-diamond/copper-alumina coating after grinding tests with varying material removal $\left(\mathrm{a}_{\mathrm{e}}=20 \mu \mathrm{m}\right)$ are shown in Fig. 12. Some material debris adheres on the surface of the grinding layer. Nonetheless, the bonding still holds the abrasive grains. In further investigations, the characteristics of wear depending on process parameters as well as the durability of the grinding tools should be taken into account. Therefore, macroscopic wear as well as microscopic wear of the abrasive grains should be considered.

\section{(a) Topography of the grinding layer after grinding experiments}

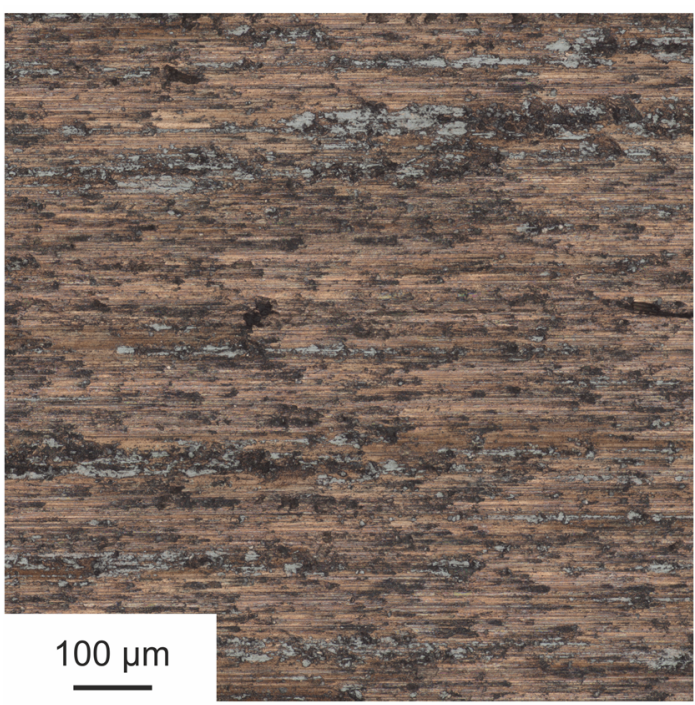

\section{(b) Height information of the topography}

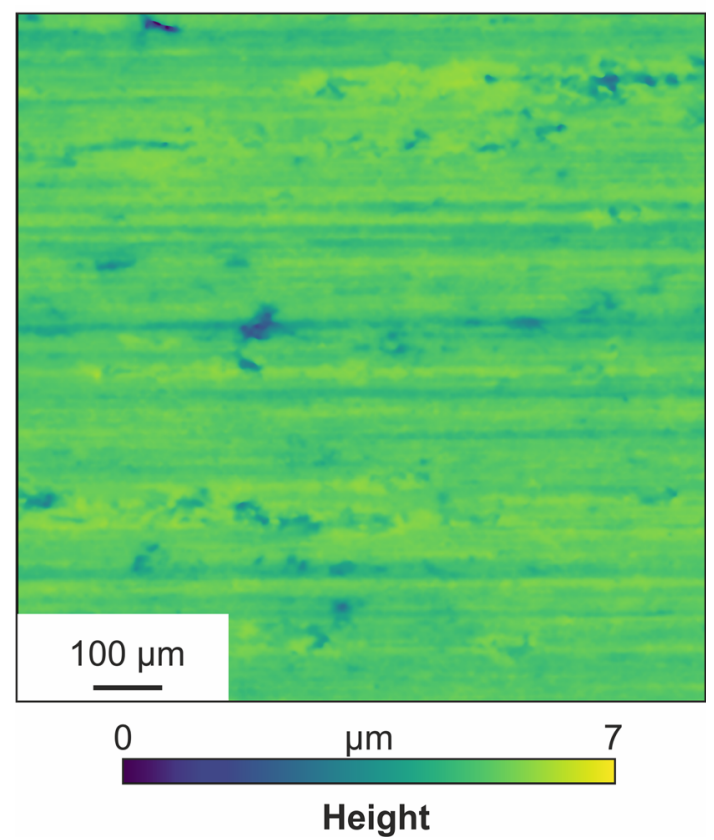

Fig. 12 Microscopic images of the grinding layer after grinding experiments

\section{Conclusion}

A powder blend of nickel-coated synthetic diamonds with a commercial copper-alumina low pressure cold spray powder was deposited on aluminum blanks by means of LP-CGS. A coating with a thickness of approximately 1.5 mm could be successfully applied on the aluminum substrates, which allows the additively manufactured tools to be subsequently dressed. Microscopic images showed that the diamonds were well embedded in the thick spray 
coating. However, the coating contained a high proportion of aluminum oxide particles, which are undesirable for the use of the grinding tool.

Heat treating the coating system resulted in a material bond between the copper-based coating and the aluminum substrate in the form of a diffusion layer. However, this layer is very thin and could only be found localized, which is attributed to the oxide layer on the aluminum substrate, which was not completely removed by the cold gas spraying process.

The first investigations concerning the dressing of a nickel-diamond/copper-alumina coating in the application as grinding layer show that common dressing strategies using silicon carbide dressing tools are a suitable solution for the conditioning of the grinding wheel. Moreover, the first grinding tests provide promising results with regard to the achievable surface roughness. Nonetheless, the first tests reveal a high research potential especially concerning the process and wear behavior of the novel grinding layers.

Future studies should investigate the possibility of embedding pure hard material particles in a pure copper matrix, e.g., by means of high-pressure cold gas spraying, in order to be able to produce a tool with more homogeneous properties promising a more predictable behavior. Furthermore, a separate injection of both the hard material and the matrix material in the cold spray gun should be considered to prevent a segregation during the powder feeding process. Moreover, future research should focus on the central question whether higher grain sizes are processable with the low-pressure or high-pressure cold gas spraying processes, in order to gain further information in the field of conventional grinding processes. Regarding the dressing process, questions concerning the influence of varying dressing strategies on the topography of the nickel-diamond/copper-alumina coating and profile arise.

Open Access This article is licensed under a Creative Commons Attribution 4.0 International License, which permits use, sharing, adaptation, distribution and reproduction in any medium or format, as long as you give appropriate credit to the original author(s) and the source, provide a link to the Creative Commons licence, and indicate if changes were made. The images or other third party material in this article are included in the article's Creative Commons licence, unless indicated otherwise in a credit line to the material. If material is not included in the article's Creative Commons licence and your intended use is not permitted by statutory regulation or exceeds the permitted use, you will need to obtain permission directly from the copyright holder. To view a copy of this licence, visit http://creativecommons. org/licenses/by/4.0/.

Funding Open Access funding enabled and organized by Projekt DEAL.

\section{References}

1. R.N. Raoelison, Y. Xie, T. Sapanathan, M.P. Planche, R. Kromer, S. Costil and C. Langlade, Cold Gas Dynamic Spray Technology: a Comprehensive Review of Processing Conditions For Various Technological Developments Till to Date, Addit. Manuf., 2018, 19, p 134-159.

2. M. Grujicic, C.L. Zhao, W.S. DeRosset and D. Helfritch, Adiabatic Shear Instability Based Mechanism For Particles/Substrate Bonding in the Cold-Gas Dynamic-Spray Process, Mater. Design, 2004, 25(8), p 681-688.

3. M. Hassani-Gangaraj, D. Veysset, V.K. Champagne, K.A. Nelson and C.A. Schuh, Adiabatic Shear Instability Is Not Necessary For Adhesion in Cold Spray, Acta Materialia, 2018, 158, p 430-439.

4. H. Assadi, F. Gärtner, T. Klassen and H. Kreye, Comment on 'Adiabatic Shear Instability Is Not Necessary For Adhesion in Cold Spray,' Scripta Materialia, 2019, 162, p 512-514.

5. M. Hassani-Gangaraj, D. Veysset, V.K. Champagne, K.A. Nelson and C.A. Schuh, Response to Comment on "Adiabatic Shear Instability Is Not Necessary For Adhesion in Cold Spray," Scripta Materialia, 2019, 162, p 515-519.

6. R.N. Raoelison, C. Verdy and H. Liao, Cold Gas Dynamic Spray Additive Manufacturing Today: Deposit Possibilities, Technol. Solt. Viable Appl., Mater. Design, 2017, 133, p 266-287.

7. W.F. Ding, J.H. Xu, Z.Z. Chen, C.Y. Yang, C.J. Song and Y.C. Fu, Fabrication and Performance of Porous Metal-Bonded Cbn Grinding Wheels Using Alumina Bubble Particles As PoreForming Agents, Int. J. Adv. Manuf. Technol., 2013, 67(5-8), p 1309-1315.

8. X.-T. Luo and C.-J. Li, Thermal Stability of Microstructure and Hardness of Cold-Sprayed Cbn/Nicral Nanocomposite Coating, $J$. Therm. Spray Tech., 2012, 21(3-4), p 578-585.

9. X.-T. Luo and C.-J. Li, Large Sized Cubic Bn Reinforced Nanocomposite With Improved Abrasive Wear Resistance Deposited By Cold Spray, Mater. Design, 2015, 83, p 249-256.

10. W. Tillmann, E. Vogli and J. Nebel, Development of Detonation Flame Sprayed Cu-Base Coatings Containing Large Ceramic Particles, J. Therm. Spray. Tech., 2007, 16(5-6), p 751-758.

11. W. Tillmann, E. Vogli and J. Nebel, Diamond-Bronze Coatings For Grinding Applications, J. Therm. Spray. Tech., 2008, 17(5-6), p 774-781.

12. W. Tillmann, E. Vogli, J. Nebel, V. Buck and S. Reuter, Influence on Diamonds During the Spraying of Diamond-Bronze Abrasive Coatings, J Therm. Spray. Tech., 2010, 19(1-2), p 350-357.

13. W. Tillmann, C. Schaak and J. Nebel, Production of Versatile Abrasive and Wear Resistant Ni-Diamond Composite Layers By Hvof Spraying, Diamante A\&T, 2014, 76(14), p 60-65.

14. W. Tillmann, C. Schaak and A. Brinkhoff, Herstellung Von Diamant-Metall-Verbundbeschichtungen Mittels Thermischer Spritzverfahren, Therm. Spray. Bull., 2017, 69(2), p 136-142. (in German)

15. W. Tillmann, A. Brinkhoff, C. Schaak and J. Zajaczkowski, SelfSharpening-Effect of Nickel-Diamond Coatings Sprayed By Hvof, IOP Conf. Ser.: Mater. Sci. Eng., 2017, 181, p 12016.

16. W. Ding, H. Li, L. Zhang, J. Xu, Y. Fu, and H. Su, Diamond Wheel Dressing: a Comprehensive Review, J. Manuf. Sci. Eng., 2017, 139(12), p 121006-1-121006-25. https://doi.org/10.1115/1. 4037991.

17. K. Wegener, H.-W. Hoffmeister, B. Karpuschewski, F. Kuster, W.-C. Hahmann and M. Rabiey, Conditioning and Monitoring of Grinding Wheels, CIRP Annals, 2011, 60(2), p 757-777.

18. K.H. Ko, J.O. Choi and H. Lee, Characteristics of Cold Sprayed Dendritic $\mathrm{Cu}$ Coatings, Surface Engineering, 2016, 32(9), p 650-654. 
19. H. Koivuluoto and P. Vuoristo, Effect of Powder Type and Composition on Structure and Mechanical Properties of $\mathrm{Cu}+$ A12o3 Coatings Prepared By Using Low-Pressure Cold Spray Process, J Therm Spray Tech, 2010, 19(5), p 1081-1092.

20. J. Pattison, S. Celotto, A. Khan and W. O'Neill, Standoff Distance and Bow Shock Phenomena in the Cold Spray Process, Surface Coat Technol., 2008, 202(8), p 1443-1454.

21. M. Grujicic, C.L. Zhao, C. Tong, W.S. DeRosset and D. Helfritch, Analysis of the Impact Velocity of Powder Particles in the Cold-Gas Dynamic-Spray Process, Mater. Sci. Eng. A, 2004, 368(1-2), p 222-230.

22. S. Yin, R. Jenkins, X. Yan and R. Lupoi, Microstructure and Mechanical Anisotropy of Additively Manufactured Cold Spray Copper Deposits, Mater. Sci. Eng.: A, 2018, 734, p 67-76.
23. K. Yang, W. Li, X. Yang, Y. Xu and A. Vairis, Effect of Heat Treatment on the Inherent Anisotropy of Cold Sprayed Copper Deposits, Surface Coatings Technol., 2018, 350, p 519-530.

24. Kipp, M.; Dreier, J.; Biermann, D., Einsatzuntersuchungen zum Polierschleifen von Hartmetall mit elastisch gebundenen Diamantschleifscheiben, Jahrbuch Schleifen, Honen, Läppen und Polieren - Verfahren und Maschinen, 69th edn., Hoffmeister, H.W.; Denkena, B. (Ed.), Vulkan-Verlag GmbH, 2020, p 270-278. (in German)

Publisher's Note Springer Nature remains neutral with regard to jurisdictional claims in published maps and institutional affiliations. 